\title{
Work Values, Satisfaction and Self-Efficacy of College Student Voluntourists in Southern China
}

\author{
Haiming $\mathrm{Chen}^{1}, \mathrm{Li} \mathrm{Xi}^{2}$ \& Jinlin $\mathrm{Zhao}^{3}$ \\ ${ }^{1}$ Faculty of Tourism and Historical Culture, ZhaoQing University, China \\ ${ }^{2}$ Faculty of International Tourism and Management, City University of Macau, China \\ ${ }^{3}$ Florida International University, Florida, USA \\ Correpondence: Li Xi, Faculty of International Tourism and Management, City University of Macau, China.
}

Received: August 7, 2018 Accepted: September 11, $2018 \quad$ Online Published: November 24, 2018

doi:10.5539/ijms.v10n4p86 URL: https://doi.org/10.5539/ijms.v10n4p86

\begin{abstract}
The researchers surveyed college voluntourists in Southern China, who participated in a tourism destination evaluation. This research aimed to empirically study the self-efficacy of the voluntourists. The basis of this voluntourism research is structured around work value, job satisfaction, self-efficacy in participating in the voluntourism activity. The research confirms that the voluntourist's work values significantly impact their job satisfaction and their self-efficacy. This research also indicates that voluntourism effectively stimulates self-awareness, interpersonal communication, meaningful work experiences, and toleration of setbacks.
\end{abstract}

Keywords: voluntourism, work values, job satisfaction, self-efficacy

\section{Introduction}

Volunteer tourism or "voluntourism", a new trend of tourism, promotes cultural communication among different regions, facilitates economic development of tourism destinations and delivers long-term benefits to the volunteers themselves. Voluntourism has become a new phenomenon in China. In August 2014, the State Council of China issued The Opinions on Promoting the Reform and Development of Tourism Industry, where it suggests that institutions of higher education should facilitate research and study tours during winter and summer vacation. The policy has provided the platform and opportunity for college student participation in volunteer tourism, which effectively: broadens their horizons, nurtures their practical abilities, and builds their personal skill sets through travelling. Many college students have begun to take part in volunteer tourism programs in China; however, there is no research in student participation of volunteer tourism in China. The researchers want to investigate the relationship among work value, satisfaction and self-efficacy of college student voluntourists. So the propose of this research is let young people catch sight of that you can get which achievement such as self-affirmation, social identification, partnership, tourism gains and so on, and then you can also hoisting capacity as self-awareness, interpersonal fusion, working practice and toleration of setbacks, and tell them you must set up what kind of point of view before join in the voluntoursim.

\section{Literature Review}

\subsection{Voluntourism}

Voluntourism is the type of tourism, which integrates voluntary service and tourism (Corti, Marola, \& Castro, 2010). Voluntourists can experience more in-depth tourism, gain mental satisfaction and a sense of honor through unconditionally contributing their time, energy and money in favor of others or public interests. Voluntourism benefits both voluntourists and tourist destinations. This type of tourism is regarded as a form of sustainable tourism and alternative tourism (Gard McGehee, 2002). Voluntourism promotes cultural exchange, stimulates the local development of tourist destinations, and brings long-term interests to voluntourists. One of the major motivations of voluntourists is the sense of responsibility and mission (Atkins, 2012), which provokes deep thought and reflection. Moreover, voluntourism encourages sympathy for others, enriches self-development and self-actualization (Stebbins \& Graham, 2004). According to Stebbins (2007), volunteer tourism, a form of serious leisure, provides voluntourists the opportunity to achieve high levels of self-esteem and self-expression. Voluntourism also boosts interpersonal skills and delivers a true sense of belonging to the voluntourist. 


\subsection{Concept and Dimensions of Work Value}

The work values that are clearly identified through voluntourism research are altruism and rational self-interest -Altruism motivates voluntourists actively and autonomously to participate in voluntourism with a sense of responsibility (Sin, 2009). Moreover, voluntourists are provided with the opportunity to enrich their inner world and satisfy their higher spiritual need (Stebbins \& Graham, 2004). The rational self-interest is the tourism experience itself. Voluntourists seek a deeper tourism experience that brings mental satisfaction instead of simple sightseeing (Lepp, 2008), therefore, voluntourism is regarded as a type of positive tourism or ecotourism which emphasizes sustainability, responsibility and instructiveness behind the tourism (Wearing, 2001).

By referring to the research findings of Wollack, Goodale, Wijting, and Smith (1971), research on motivations of voluntourists (Schram, 1985; Wright, 2014), and taking the actual experiences of voluntourists into consideration, this research divides Work Values into four dimensions - traveling and studying, social respect, interpersonal synchrony, and the experience of altruism.

\subsection{Concept and Dimensions of Job Satisfaction}

Job satisfaction of voluntourists depends on the satisfaction level of the voluntary services, the psychological conditions of the job and the working environments, which could be positive or negative (Wanous \& Lawler, 1972). High job satisfaction promotes interest, effort and voluntary cooperation of staffs. Moreover, it encourages higher loyalty, discipline and solidarity (Khan, Asghar, \& Zaheer, 2014). Long-term interest for the voluntourists is important. Voluntourists may experience distinctive in-depth tourism and realize a higher value of altruism (Sin, 2009). Therefore, voluntourism facilitates self-actualization, enrichment, entertainment, sense of achievement, confidence, and interpersonal relationship enhancement. Voluntourism encourages passion for volunteering (McGehee, 2014). Several researchers categorized the job satisfaction of volunteers (Aves, 1972; Briggs, 1981; Khan et al., 2014; Upadhyay \& Vashishtha, 2014). By integrating the research findings of recent years, the authors reduced the five dimensions of job satisfaction among college student voluntourists to be self-affirmation, social identification, entertainment, partnership, and tourism benefits.

\subsection{Concept and Dimensions of Self-efficacy}

The concept of self-efficacy originates from psychological and social sciences; Bandura (1977) emphasized that the three determining factors of human behaviors are cognition, behavior, and environment. The interactions of the three factors are what define human behavior. Self-assessment of completing a task determines self-efficacy. Bandura (2006) indicated that effort and time one is willing to devote to a task is directly related to self-efficacy. Individuals with higher self-efficacy would be more positive and allocate more time to work. Therefore, self-efficacy is an individual's belief of his capacity and worth, and it was came from self awareness, interpersonal fusion, job skills, and ability to deal with difficult setbacks that get after completion of the task (Locke, Frederick, Lee, \& Bobko, 1984). Individuals with higher self-efficacy are generally more confident and perform better at work. Based on the research findings of Bandura and other researchers, the authors identified four dimensions of self-efficacy - self-awareness, interpersonal communication, work experience, and toleration of setbacks. These four dimensions determine the voluntourist's confidence in their accomplishment of voluntary services.

\subsection{Relationship among Work Value, Job Satisfaction and Self-efficacy}

The significant correlation between work value and job satisfaction has been proved by many researches. Hegney, Plank, and Parker (2003) found that internal and external work values both affect job satisfaction. Farrell, Johnston, and Twynam (1998) studied motivations and job satisfaction of 300 games volunteers and found correlation between volunteer motivation and job satisfaction. Though motivation is not exactly equivalent to work value, the work value of voluntourists largely contains and decides their motivation.

The volunteers considered the project and its impacts as positive or very positive for themselves and for other groups, About $82 \%$ of respondents believed that they were capable for the work carried out in school, Voluntourists, not only participate in an educational project in the country, contributing to local education, but they are also recipients of an experience that provides personal growth and self discovery. Events that in another type of tourism usually do not occur. it represents an opportunity, through learning experience, of having a good job in the future, that will provide them a better life than their current one(Corti et al., 2010).

It could be summarized on the basis of relevant studies that the job satisfaction of voluntourists largely includes self-growth and studying (Aves, 1972; Briggs, 1981; Farrell et al., 1998; Telep, 1986). According to Markus, Howard, and King (1993), servants experienced service learning are more inclined to give their potentials to full play. Kozeracki (2000) induced that the effects of service learning include facilitating and promoting learning, 
value clarification, sense of community identification, sense of citizen responsibilities, awareness of multicultural consciousness, school involvement in communities, critical thinking and problem solving abilities, confidence and self-efficacy, career opportunities and development. It could be concluded that service learning, as the basis of job satisfaction, significantly affects self-efficacy and this research would examine the influence of job satisfaction on self-efficacy.

\section{Research Methodology}

This study used quantitative research methods, research data were gathered through random sampling questionnaire, SPSS 21.0 was adopted to analyze the data, and AMOS21.0 was adopted to build and verify theoretical model.

\subsection{Research Hypotheses}

Through literature review, this research aims to study work value, job satisfaction and self-efficacy of voluntourists. Moreover it analyzes the relationship among the three variables. Hypotheses are as follows:

H1: Work value of voluntourists has significant impacts on their job satisfaction;

H2: Work value of voluntourists has significant impacts on their self-efficacy;

H3: Job satisfaction of voluntourists has significant impacts on their self-efficacy;

H4: The theoretical model and observed data proposed by this research are compatible.

\subsection{Research Framework}

The research framework drawn on the basis of the research hypotheses is shown as follows:

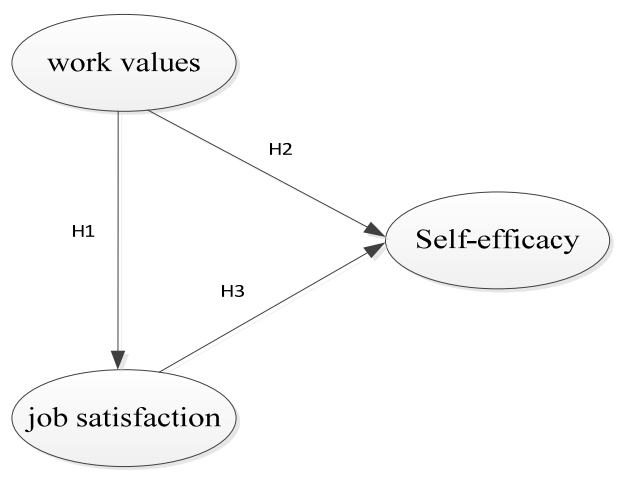

Figure 1. Research framework

\subsection{Questionnaire Design and Survey}

Based the literary review, this survey has 20 questions in regards to the four dimensions of work value: traveling and studying, social respect, interpersonal benefit, and experience of altruism. The questions are using Likert scale to find the agreement level of the respondents with 5 - highly agree and 1 highly disagree. There are 25 questions in four dimensions of satisfaction including social identification, partnership, entertainment and tourism gain with 5 - highly satisfied and 1 - highly unsatisfied. 25 questions are in four dimensions of self-efficacy: self-awareness, interpersonal communication, working experiences and toleration of setbacks with 5 highly agree and 1 highly disagree. There are some demographic questions: gender, level of education in a college, length of trip and location of the trip.

\subsection{Sample Size of the Survey}

This research surveyed a random sampling of 350 voluntourist college students in Southern China participating in the Hakka Cultural census.. The survey was conducted from 6th November 2013 to 6th March 2014, 350 paper questionnaires were distributed. 322 pieces were collected and the valid return rate was $92 \%$.

\subsection{Data Analysis Methods}

SPSS 21.0 software is adopted as the analysis tool for descriptive analysis, reliability and validity analysis and regression analysis. AMOS21.0 software is also adopted to analyze and examine the compatibility of theoretical model and observed data proposed by this research. 


\section{Analysis and Results}

\subsection{Reliability and Validity Analysis of the Questionnaire}

\subsubsection{Validity Analysis}

The design of the questionnaire was based on the relevant literature and previous scales examined by relevant scholars and the questionnaire is in accord with the expert's validity. This research adopted height subsection of the questionnaire and the result of $\mathrm{T}$ test was $\mathrm{T}=3.909^{* * *}, \mathrm{P}=0.000$, which proved the discriminant validity of the research.

Factor analysis was adopted to examine the KMO and Bartlett of each variable, and principal component analysis was adopted to examine the component values of each dimension and option for further examination of construct validity. Table 1 shows the fair validity of each option.

Table 1. Factor analysis of each variable

\begin{tabular}{llllll}
\hline variable & dimension & KMO & Bartlett & P & component \\
\hline \multirow{5}{*}{ work value } & traveling and studying & 0.907 & 2598.791 & 0.000 & $0.939-0.974$ \\
& experience of altruism & 0.914 & 2983.717 & 0.000 & $0.966-0.977$ \\
& social respect & 0.921 & 3364.861 & 0.000 & $0.963-0.985$ \\
& interpersonal assistance & 0.917 & 4183.729 & 0.000 & $0.986-0.992$ \\
\hline \multirow{5}{*}{ Job Satisfaction } & self-affirmation & 0.925 & 2741.642 & 0.000 & $0.956-0.976$ \\
& social identification & 0.918 & 2877.471 & 0.000 & $0.966-0.977$ \\
& partnership & 0.888 & 3565.538 & 0.000 & $0.972-0.985$ \\
& entertainment & 0.903 & 3815.431 & 0.000 & $0.976-0.989$ \\
& Tourism gains & 0.915 & 4172.524 & 0.000 & $0.986-0.993$ \\
\hline \multirow{5}{*}{ Self-efficacy } & self-awareness & 0.955 & 4520.189 & 0.000 & $0.943-0.979$ \\
& interpersonal communication & 0.905 & 4283.831 & 0.000 & $0.971-0.982$ \\
& working Experiences & 0.918 & 4064.437 & 0.000 & $0.688-0.985$ \\
& Toleration to setbacks & 0.952 & 5586.822 & 0.000 & $0.989-0.993$ \\
\hline
\end{tabular}

Extract Method: principal component.

Source: result of SPSS 21.0 analysis in this research.

\subsubsection{Reliability Analysis}

Reliability analysis on different dimensions of each variable was adopted to examine the uniformity of the questionnaire. Result of the analysis shows that reliability $\alpha$ value was above 0.946 as shown in Table 2 .

Table 2. Reliability analysis of dimensions of each variable

\begin{tabular}{llll}
\hline variable & dimension & Cronbach's Alpha & subtotal \\
\hline \multirow{3}{*}{ work value } & traveling and studying & 0.978 & \\
& experience of altruism & 0.985 & 0.994 \\
& social respect & 0.989 & \\
& interpersonal assistance & 0.994 & \\
job satisfaction & self-affirmation & 0.981 & 0.995 \\
& social identification & 0.984 & \\
& partnership & 0.989 & \\
& entertainment & 0.992 & 0.992 \\
self-efficacy & Tourism gains & 0.994 & \\
& Self-awareness & 0.987 & \\
\hline Total & interpersonal communication & 0.990 & \\
\hline
\end{tabular}

Source: result of SPSS 21.0 analysis in this research. 


\subsection{Descriptive Analysis}

Among the voluntourists, 134 or $41.6 \%$ were male and 188 or $58.4 \%$ were female students. 290 or $90.1 \%$ were sophomore students. 32 students or about $10 \%$ were freshmen or junior students. No senior students participated in the survey as it was their period of job hunting before graduation. 148 students or $46 \%$ conducted voluntourism for $1-3$ days, 120 or $37.3 \%$ for $4-6$ days, 30 students or $9.3 \%$ for $7-9$ days and 24 students or $7.5 \%$ for 10 or more days.

This research performed average values statistics of all items in different dimensions of each variables and calculated the average values of each dimension. The average values of interpersonal assistance and experience of altruism are rather higher in the dimensions of work value, which reached 4.49 and 4.32, partnership and tourism gains are rather higher in the dimensions of job satisfaction, which reached 4.43 and 4.41 , working practice and toleration of setbacks are rather higher in the dimensions of self-efficacy, which reached 4.46 and 4.40 .

\subsection{Regression analysis}

Regression analysis was used in this research for the causality analysis of each variable including H1: Work value of voluntourists has significantly impacts on their job satisfaction, $\mathrm{H} 2$ : Work value of voluntourists has significantly impacts on their self-efficacy, and H3 Job satisfaction of voluntourists has significantly impacts on their self-efficacy. The analysis results are shown in Table 3 in which regression coefficients are all greater than 0.9 and sig. value all less than 0.001 . It is demonstrated that all regression relationships are tenable through examination.

Table 3. Regression analysis of each variable

\begin{tabular}{llll}
\hline Relationship among variables & Adj R Squared & B value & sig. \\
\hline Work value $\rightarrow$ job satisfaction & 0.975 & 0.987 & 0.000 \\
Work value $\rightarrow$ self-efficacy & 0.965 & 0.983 & 0.000 \\
job satisfaction $\rightarrow$ self-efficacy & 0.976 & 0.988 & 0.000 \\
\hline
\end{tabular}

Source: result of SPSS 21.0 analysis in this research.

\subsection{Mediation effect Analysis}

First, through linear regression analysis, found the change of Work Values can significantly explained the change of Job satisfaction, $\mathrm{P}=0.000, \mathrm{R} 2=0.965$; then, found the change of Job satisfaction can significantly explained the change of Self-efficacy, $\mathrm{P}=0.000, \mathrm{R} 2=0.975$; When the control of the above two paths, The causal relationship between Work Values with Self-efficacy has weakened, $P=0.000, R=0.294$. As a result, the mediation effect was established. Job satisfaction was the intermediary variables between Work Values with Self-efficacy

\subsection{Model building and Fitting Degree Analysis}

The maximum likelihood method was adopted to analyze the diagrammatic figures on work value, job satisfaction, and self-efficacy set in advance in AMOS 21.0. After the calculation of estimated values, the model could smoothly realize the convergence and identification of a standardized diagrammatic figure, as shown in Figure 2. 


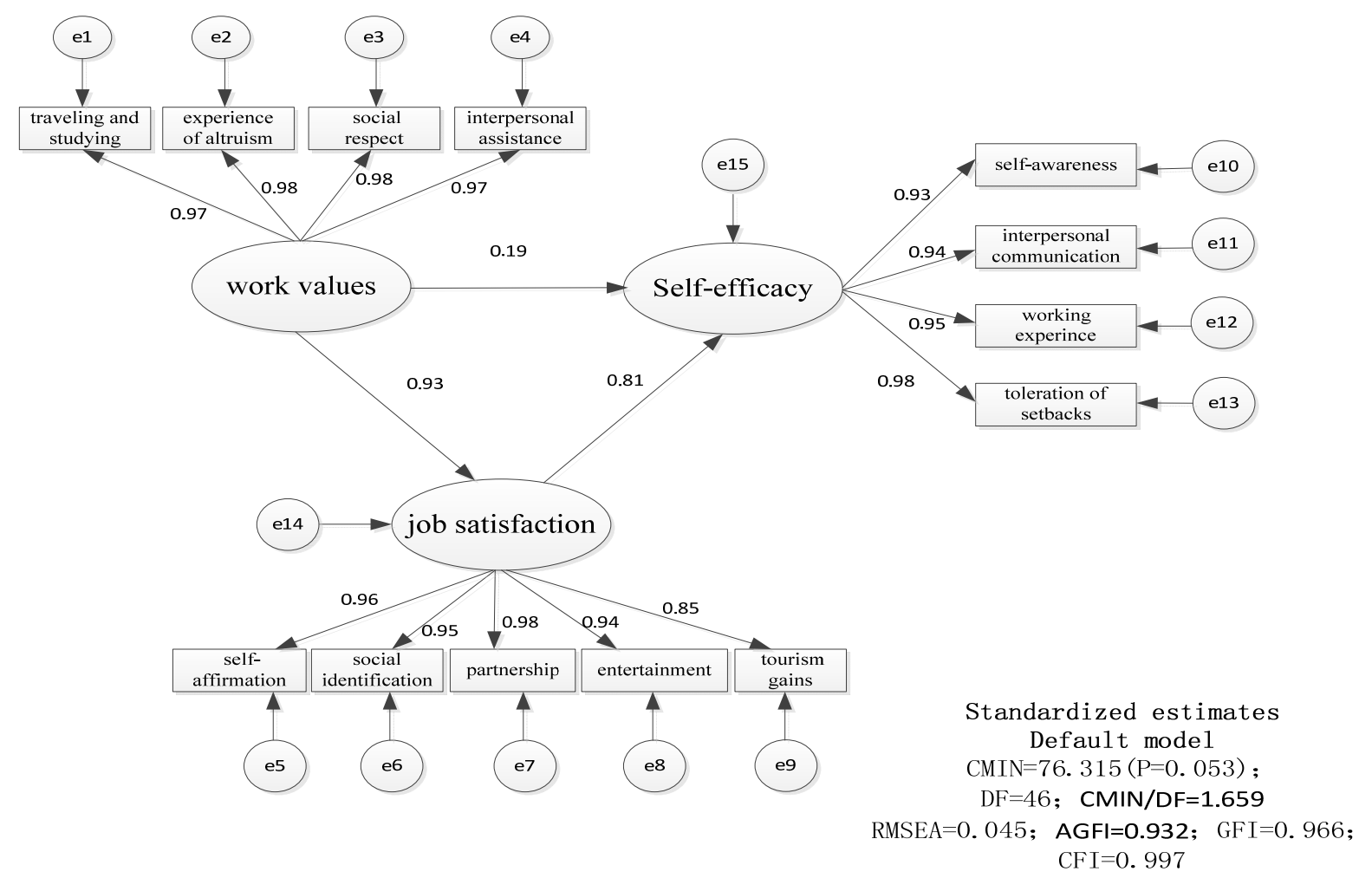

Figure 2. Theory model

Source: result of AMOS 21.0 analysis in this research.

AMOS 21.0. was used in this research for the analysis of H4-compatibility of the theoretical model and observed data proposed by this research. The analysis results proved the integrity of coefficient of each path relationship which conformed to the hypothesized path. $\mathrm{CMIN}=76.315$, significance probability $\mathrm{P}=0.053>0.05$, fall short of the level of significance, accepting null hypothesis, the hypothesized diagrammatic figure was compatible with observed data proposed by this research, AGFI $=0.932>0.900, \mathrm{CMIN} / \mathrm{DF}=1.659<4$, RMSEA $=0.045<0.05 ; \mathrm{GFI}=0.966>0.900 ; \mathrm{CFI}=0.997>0.900$, as shown in Figure 2. All data pointers reached the standard of model compatibility and proved a good compatibility of the theoretical models and observed data proposed by this research. It is demonstrated that $\mathrm{H} 4$ - compatibility of the theoretical model and observed data proposed by this research is acceptable through examination.

\section{Discussion and Suggestion}

\subsection{H1, H2 and H3 Are Accepted}

Regression analysis indicates a significant relationship between work value and job satisfaction with $\beta$ value reached 0.987 and Adj R Squared value reached 0.975, displaying a positive affect of vountarists' work value on their job satisfaction; significant relationship between work value and self-efficacy with $\beta$ value of 0.983 and Adj $\mathrm{R}$ Squared value 0.965 , which showed positive relationship between voluntourist work values on their self-efficacy; significant relationship between job satisfaction and self-efficacy with $\beta$ value of 0.988 and Adj $R$ Squared value of 0.976 , which showed positive affect of voluntourist's job satisfaction on their self-efficacy.

It concludes that work value of voluntourists has significant impacts on their job satisfaction; work values of voluntourists have significantly impacts on their self-efficacy, and Job satisfaction of voluntourists has significant impacts on their self-efficacy.

\subsection{H5 Is Accepted}

The AMOS analysis in this research proved the theoretical models of work value, job satisfaction and self-efficacy of voluntourists and observed data proposed by this research are fairly compatible.

The standardized regression coefficient in the models is the path coefficient among variables. The path coefficient of work value to job satisfaction was 0.93 ; the path coefficient of work value to self-efficacy was 0.19 ; 
and the path coefficient of job satisfaction to self-efficacy was 0.81 . The values of the three path coefficients were all positive numbers, which indicates their positive direct impacts on criterion variables, though varied in degree. Among the path coefficients, the path coefficient of work value to job satisfaction and the path coefficient of job satisfaction to self-efficacy were higher and path coefficient of work value to self-efficacy was lower.

Among all the dimensions of work value, traveling and studying, experience of altruism, social respect, and interpersonal assistance are 0.97、0.98、0.98 and 0.97 respectively, and had higher coefficients on the variable of work value. Among all the dimensions of job satisfaction, self-affirmation, social identification, partnership, entertainment, and tourism gains are $0.96 、 0.95 、 0.98 、 0.94$ and 0.85 respectively, and had higher coefficients on the variable of job satisfaction. Among all the dimensions of self-efficacy, self-awareness, interpersonal communication, working experience, and toleration of setbacks are 0.93、0.94、0.95 and 0.98, and had higher coefficients on the variable of self-efficacy. It concludes by this research through AMOS analysis and above discussions that H4: the theoretical models and observed data proposed by this research are compatible was accepted.

\subsection{Conclusion}

The findings of this research conclude that college student voluntourists attain self-affirmation, social identification, partnership, entertainment, and tourism benefits though volunteer tourism activities. The work values and job satisfaction achieved during the voluntourism experience bolstered their self-efficacy. It is important to recognize the high quality benefits of participating in voluntourism; self-awareness, interpersonal communication, meaningful working experiences, and the ability to tolerate setbacks are attained through volunteer tourism. Colleges and universities should further encourage and facilitate voluntourism, which would effectively help students broaden their horizons, hone their practical abilities and promote their personal qualities. The quality of voluntourism should also be optimized consistently so that voluntourists continue to have positive experiences in job satisfaction and self-efficacy.

The authors suggest that more Chinese college students actively participate in voluntourism in order to enrich work values, enhance traveling and studying, experience altruism, gain social respect, find high quality interpersonal communication, and increase their toleration of setbacks. Moreover these voluntourism experiences will help facilitate cultural exchanges as well as advance the social, economical and cultural development of tourism destinations.

\section{References}

Atkins, S. G. (2012). Smartening-up Voluntourism: SmartAid's Expansion of the Personality-focused Performance Requirements Form (PPRF). International Journal of Tourism Research, 14(4), 369-390. https://doi.org/10.1002/jtr.875

Aves, G. M. (1972). The Voluntary Worker in the Social Services. Small Group Research, 3(1), 76-76.

Bandura, A. (1977). Self-efficacy: toward a unifying theory of behavioral change. Psychological review, 84(2), 191. https://doi.org/10.1037/0033-295X.84.2.191

Bandura, A. (2006). Guide for constructing self-efficacy scales. Self-efficacy beliefs of adolescents, 5(307-337).

Briggs, D. L. (1981). On satisfying the volunteer and the paid employee: any differences? Volunteer administration, 14(4), 1.

Corti, I. N., Marola, P. N., \& Castro, M. B. (2010). Social inclusion and local development through european voluntourism: A case study of the project realized in a neighborhood of morocco. American Journal of Economics and Business Administration, 2(3), 221. https://doi.org/10.3844/ajebasp.2010.221.231

Farrell, J. M., Johnston, M. E., \& Twynam, G. D. (1998). Volunteer motivation, satisfaction, and management at an elite sporting competition. Journal of Sport Management, 12(4), 288-300. https://doi.org/10.1123/jsm.12.4.288

Gard McGehee, N. (2002). Alternative tourism and social movements. Annals of Tourism Research, 29(1), 124-143. https://doi.org/10.1016/S0160-7383(01)00027-5

Hegney, D., Plank, A., \& Parker, V. (2003). Nursing workloads: the results of a study of Queensland nurses. Journal of Nursing Management, 11(5), 307-314. https://doi.org/10.1046/j.1365-2834.2003.00376.x

Khan, S., Asghar, M., \& Zaheer, A. (2014). Influence of leadership style on employee job satisfaction and firm financial performance: a study of banking sector in islamabad, pakistan. Actual Problems of Economics, 
155(5), 374-384.

Kozeracki, C. A. (2000). ERIC Review: Service learning in the community college. Community College Review, 27(4), 54-70. https://doi.org/10.1177/009155210002700405

Lepp, A. (2008). Discovering self and discovering others through the Taita Discovery Centre volunteer tourism programme, Kenya. Journeys of discovery in volunteer tourism: International case study perspectives, 86-100.

Locke, E. A., Frederick, E., Lee, C., \& Bobko, P. (1984). Effect of self-efficacy, goals, and task strategies on task performance. Journal of Applied Psychology, 69(2), 241. https://doi.org/10.1037/0021-9010.69.2.241

Markus, G. B., Howard, J. P., \& King, D. C. (1993). Notes: Integrating community service and classroom instruction enhances learning: Results from an experiment. Educational evaluation and policy analysis, 15(4), 410-419. https://doi.org/10.3102/01623737015004410

McGehee, N. G. (2014). Volunteer tourism: evolution, issues and futures. Journal of Sustainable Tourism, 22(6), 847-854. https://doi.org/10.1080/09669582.2014.907299

Mobley, W. H. (1977). Intermediate linkages in the relationship between job satisfaction and employee turnover. Journal of Applied Psychology, 62(2), 237-240. https://doi.org/10.1037/0021-9010.62.2.237

Schram, V. R. (1985). Motivating volunteers to participate. Motivating Volunteers. Vancouvert Volunteer Centre, 13-30.

Sin, H. L. (2009). Volunteer tourism- “involve me and I will learn"? Annals of Tourism Research, 36(3), 480-501. https://doi.org/10.1016/j.annals.2009.03.001

Stebbins, R. A. (2007). Serious leisure: A perspective for our time (Vol. 95). Transaction Publishers.

Stebbins, R. A., \& Graham, M. (2004). Volunteering as leisure/leisure as volunteering: An international assessment. Cabi. https://doi.org/10.1079/9780851997506.0000

Telep, V. G. (1986). The relationship of volunteer perception of organizational climate to volunteer work satisfaction. Virginia Commonwealth University.

Upadhyay, P. R., \& Vashishtha, A. C. (2014). Effect of Anasakti and Level of Post on Job Satisfaction of Employees.

Wanous, J. P., \& Lawler, E. E. (1972). Measurement and meaning of job satisfaction. Journal of Applied Psychology, 56(2), 95-105. https://doi.org/10.1037/h0032664

Wearing, S. (2001). Volunteer tourism: Experiences that make a difference. Cabi. https://doi.org/10.1079/9780851995335.0000

Wollack, S., Goodale, J. G., Wijting, J. P., \& Smith, P. C. (1971). Development of the survey of work values. Journal of Applied Psychology, 55(4), 331. https://doi.org/10.1037/h0031531

Wright, H. (2014). Volunteer tourism and its (mis) perceptions: A comparative analysis of tourist/host perceptions. Tourism and Hospitality Research, 1467358414527984.

\section{Copyrights}

Copyright for this article is retained by the author, with first publication rights granted to the journal.

This is an open-access article distributed under the terms and conditions of the Creative Commons Attribution license (http://creativecommons.org/licenses/by/4.0/). 